\title{
Evidence of social effects on mate choice in vertebrates
}

\author{
Bennett G. Galef Jr. *, David J. White ${ }^{1}$ \\ Department of Psychology, McMaster University, 1280 Main Street West, Hamilton, ON, Canada L8S 4K1
}

Received 1 September 1999; received in revised form 26 January 2000; accepted 31 January 2000

\begin{abstract}
Study of determinants of mate selection by animals has a long history in evolutionary biology and behavioural ecology. However, only during the past decade have investigators begun to conduct experiments exploring the various ways in which observation of the behaviour of others might influence mate selection. Here, we review both field and laboratory studies of behavioural processes that underlie non-independence in mate choice, discussing both direct and indirect social influences on mate selection. We focus on laboratory studies in which guppies and Japanese quail, species that have received greatest attention from investigators, have served as subjects. Although much is now known about how public information can affect mate selection in controlled environments, there are still significant gaps in our knowledge of whether and how such information contributes to mate selections by members of free-living populations. (C) 2000 Elsevier Science B.V. All rights reserved.
\end{abstract}

Keywords: Mate choice; Social learning; Vertebrate

\section{Introduction}

Life is a nearly endless series of choices each of which can, at least in principle, affect the frequency with which an individual's genes will be represented in future generations.

Three sources of information are of potential use in choosing between alternatives (Galef, 1976). First, every animal is born with sensory-affective systems, products of evolutionary history that bias responses to stimuli. For decades, ethol-

\footnotetext{
* Corresponding author.

${ }^{1}$ Present address: Department of Psychology, Indiana University, Bloomington, IN 47401, USA.
}

ogists have analyzed such sensory-affective systems and the motor behaviours they excite.

Second, an individual may have a prior history of experience with stimuli that are, to greater or lesser degree, like those to which it must now respond in choosing a course of action. Experimental psychologists have studied effects of individual experiences on response to stimuli for more than a century.

Last, an animal facing a choice may have access to information about the choices others have made when faced with similar decisions. Study of such social influences on behaviour are relatively few, and it is only during the last decade that the subject of the present review, effects of social 
influences on mate choices of animals, has been a focus of experimental investigation.

Theoreticians tell us that when choosing a course of action the relative utility of inherent sensory-affective biases and of information acquired either individually or socially is determined by the rate at which the environment changes (e.g. Boyd and Richerson, 1985; Laland et al., 1993, 1996). However, it is well to keep in mind that, at least in vertebrates with relatively complex nervous systems, any choice is likely to reflect an elaborate interplay of congenital sensory-affective systems, relevant individual experiences and 'public information' (Valone, 1989). Thus, focus here on social influences on mate choice should not be taken to imply that social learning is of primary importance in mate selection. Indeed, until quite recently, it was not even well established that observation of the behaviour of others could affect an individual's choice of mate, and until very recently indeed, it was not known how social influence, whether 'direct' or 'indirect' (Galef, 1985), affected the mate choices of members of any species.

\section{Direct and indirect social influences on mate choice}

Pruett-Jones (1992), p. 1000) has defined direct social influence on mate choice by females (i.e. 'mate-choice copying') as occurring whenever 'the conditional probability of choice of a given male by a female is either greater or less than the absolute probability of choice depending on whether that male mated previously or was avoided, respectively'. Dugatkin (1996a,b), p. 87) has proposed qualifying Pruett-Jones (1992) definition by adding the condition that 'the information about a male's mating history (or some part of it) must be obtained by the female via observation' [presumably of the male interacting with other females].

Other forms of social influence on female mate choice, less direct than mate-choice copying per se, can be responsible for instances of socially biased mate selection that, at first glance, appear to be direct. For example, females of a species are often attracted to one another and tend to move about in groups. If so, presence of one female on a male's territory might increase the probability that other females will be there as well, and a male may therefore have opportunity to mate with a group of females whenever he has opportunity to mate with one (Keister, 1979). Or mating may cause some change in a male's subsequent appearance or behaviour making him more attractive to females (Goldschmidt et al., 1993). Or, one female may make some change in a male's territory (e.g. deposit eggs (Jamieson, 1995) or build a nest there) increasing both the territory's attraction to other females and the territory holder's probability of mating with them (Sikkel, 1989). Such indirect social effects on the mate choices of females are of biological importance because they, like direct mate-choice copying can increase both variance in male reproductive success and the opportunity for sexual selection to occur (Wade and Pruett-Jones, 1990).

\section{Roles of social interaction in mate choice}

At a proximal level of analysis, there are at least three questions that one might ask about the role of social interactions in mate choice: (1) Can social interactions, either direct or indirect, influence mate choices; (2) What behavioural processes support any particular instance of social influence on mate choice; and (3) Do social influences actually affect mate choices of free-living animals? There are, in addition, a number of interesting ultimate questions arising from consideration of: (1) how social influences impact on variance in reproductive success (e.g. Pruett-Jones, 1992 Wade and PruettJones, 1990); (2) the conditions under which mate-choice copying is an evolutionarily stable strategy (e.g. Losey et al., 1986); and (3) the role of gene-culture interaction on development of male characteristics (e.g. Kirkpatrick and Dugatkin, 1994; Laland, 1994a,b). These 'ultimate' issues have been reviewed recently in Dugatkin (1996a), and because space is limited, will not be explicitly considered here.

The first two proximal questions stated above can be answered under controlled conditions, and they are therefore surely more easily addressed than is the third. However, unfortunately, demon- 
strating that members of some species can do something in the laboratory is not at all the same thing as showing that members of that species act similarly when they are in more complex natural settings (Galef, 1984). Equally unfortunately, satisfying investigations of effects of experience, whether individual or social, on behaviour (i.e. animal learning) are difficult to conduct in natural circumstances (Galef, 1984). Consequently, we know considerably less about social influences on mate choice in free-living than in captive animals. Still, observation of the behaviour of animals in their natural habitats first suggested that social influences might be important in mate choice and motivated the laboratory studies that were to follow.

\section{Studies of free-living animals}

The frequently observed highly skewed mating success of males on avian leks (Wiley, 1991) has led several investigators to ask whether the exceptional frequency with which some males secure copulations is due to direct mate-choice copying among females (e.g. Bradbury and Gibson, 1983; Gibson et al., 1991; Hoglund et al., 1990, 1995). In grouse, the lekking birds most frequently studied in this regard, a social explanation for the singular success of some males is made more likely by females' habit of visiting leks both numerous times and in groups, thus providing ample opportunity for social influences on mate choice to occur.

\subsection{Black grouse}

Hoglund et al. (1990, 1995) examined the temporal sequence of matings by male black grouse (Tetrao tetrix) to determine whether female matings with individual males were clustered in time. They found, as expected, a markedly skewed distribution of male mating success and a tendency for individual males to obtain in rapid succession whatever copulations they did secure. The latter result is consistent with the hypothesis that females' mate choices were not independent, though it tells us little about what form non-independence takes in mate selection by female black grouse.

\subsection{Sage grouse}

Gibson et al. (1991) studied the mate choices of female sage grouse (Centrocercus urophasianus) on two leks over several years. They discovered no consistency across either years or leks in the physical characteristics of preferred males. However, they did find greater consistency in female choice of males with an increase in the number of females visiting a lek on a given morning and an increase in a male's probability of mating, if he had mated 2 days earlier, 2 days being the most frequent interval between successive lek visits by individual sage-grouse hens. Gibson et al. interpreted these effects as indicative of mate-choice copying. They argued that greater opportunity for mate-choice copying exists on days when many females are visiting and the correspondence between male intercopulatory intervals and female visiting patterns suggests that females are using information they acquired on one visit to a lek to choose a male with whom to copulate when they return 2 days later (Gibson and Hoglund, 1992).

\subsection{Fallow deer}

In many lek-breeding mammals, females tend to join males that already have large harems (Clutton-Brock et al., 1989) which could, of course, result from a tendency of females either to copy the choices of other females or to prefer to join larger herds. Clutton-Brock and McComb (1993) sought to determine whether the attraction of female fallow deer (Dama dama) to males with large harems was the result of attraction to harem holders or harem members. Females in oestrous were allowed to choose between enclosures containing either males alone, males with varying numbers of females, or females alone. Subject females preferred males with harems to lone males, but showed no preference between herds of roughly equal size with or without a male member. Further, a female that saw a male actually mating did not tend to join his harem. The data indicate that female fallow deer tend to join females not males, (perhaps to reduce predation risk, perhaps to reduce harassment by males), and any consequent skewing in male reproductive suc- 
cess would be an indirect result of a tendency of females to aggregate when in oestrous (McComb and Clutton-Brock, 1994).

\subsection{Garibaldi}

Numerous observations in both field and laboratory indicate that female members of polygynous fish species in which males care for eggs prefer to lay their eggs in males' nests that already contain eggs of other females (e.g.Fricke, 1980; DeMartini, 1987). For example Sikkel (1989) found that in the field female garibaldi (Hypsypos rubicundus) preferentially approached nests containing eggs in early stages of development before or without male courtship and were more likely to spawn in such nests than in empty nests or in nests with eggs in advanced stages of development. Field experiments in which Sikkel either stripped eggs at various stages in development from or added eggs to nests confirmed the causal effects of egg presence on mate choices of females. As in fallow deer, the evidence suggests an indirect social influence on mate selection.

\section{Laboratory studies}

\subsection{Sticklebacks}

Ridley and Rechten (1981) and Jamieson and Colgan (1989) report that female three-spined stickleback (Gasterosterous aculateatus) in the laboratory, that like female Garibaldi spawn in nests containing eggs in preference to nests that do not, are not attracted by the presence of eggs per se. Rather, male stickleback with eggs in their nests court more vigorously and are more attractive to females than are competitors without eggs in their nests (Jamieson and Colgan, 1989). On the other hand, Goldschmidt et al. (1993) have provided evidence that eggs in the nest of a male stickleback were themselves attractive to females (but see Patriquin-Meldrum and Godin, 1998).

Repeated attempts to demonstrate direct matechoice copying by female stickleback have been unsuccessful (Jamieson, 1995; Patriquin-Meldrum and Godin, 1998).

\subsection{Guppies}

The first comprehensive series of laboratory studies of social influences on mate choice is that of Dugatkin and coworkers using guppies, Poecilia reticulata, as subjects. Guppies are likely animals for studies of mate choice; in their native streams in Trinidad, they swim in mixed-sex shoals, much is known about sensory control of mate choice in the species (Houde, 1997), and guppies court and mate readily in the laboratory.

Dugatkin (1992) examined social effects on mate choice in a 10-1 aquarium located between two transparent end chambers (Fig. 1). He placed a single 'target' male in each end chamber and a 'focal' female in a transparent cylinder located in the centre of the aquarium. A removable glass partition was used to create a separate section of the aquarium in which a 'model' female could be placed. In a first experiment, focal females watched one of two target males matched for size court a model female for $10 \mathrm{~min}$, then chose between target males. Seventeen of the 20 focal females preferred the target male they had seen courting.

Results of a series of five separate 'control' experiments were used to exclude a number of indirect explanations of the phenomenon. Focal females preferred the male they had seen courting, not the end of the aquarium in which courtship occurred or the part of the tank where they had seen two fish rather than one. Target males did not become more attractive to focal females as a consequence of having courted model females,

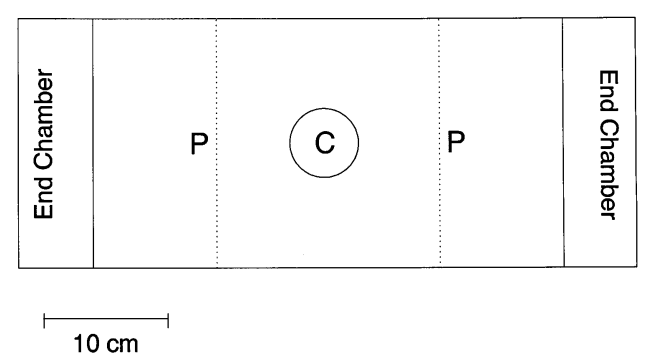

Fig. 1. Overhead schematic of aquarium used by Dugatkin to study social influences on mate choice in guppies. $C$ is transparent cylinder to hold a focal female; $P$ is a removable transparent partition used to restrain a model female. 
and so on. Indeed, all of Dugatkin (1992) data pointed to the conclusion that female guppies preferred to affiliate with males they had watched court other females.

In subsequent work carried out in collaboration with Godin, Dugatkin has found that: (1) small focal females copy the mate choices of large model females, but that large focal females do not copy the mate choices of small model females (Dugatkin and Godin, 1992); (2) after a focal female sees the inherently less attractive member of a pair of target males court a model female, that male becomes more attractive to the focal female than his partner (Dugatkin and Godin, 1993); (3) well fed, but not hungry, female guppies copy the mate-choices of others (Dugatkin and Godin, 1998); and (4) the longer a focal female sees the less attractive member of a pair of target males courting a model female, the greater the handicap in his inherent attractiveness can be overcome (Dugatkin, 1996a,b, 1998).

Published attempts to repeat demonstrations of female mate-choice copying in guppies have not used as subjects laboratory-reared descendants of individuals captured in Trinidad, and have not been successful (Brooks, 1996; Lafleur et al., 1997). The causes of these and other unpublished failures to repeat Dugatkin's observations have not been identified (Brooks, 1998).

\subsection{Sailfin mollies}

In a compelling extension of Dugatkin's studies of social influences on mate choice in guppies, Schlupp et al., (1994) found that female sailfin mollies (Poecilia latipina) prefer to mate with male sailfin mollies they have seen mating with female Amazon mollies (Poecilia formosa). Male sailfin mollies do not fertilize the ova of female Amazon mollies, can discriminate between conspecific and heterospecific females, yet mate heterospecifically in nature. Schlupp et al.'s findings provide evidence of a reproductive advantage accruing to males mating heterospecifically (Witte and Ryan, 1998); by mating heterospecifically, a male sailfin molly may increase his attractiveness to females of his own species.

\subsection{Japanese medaka}

Grant and Green (1996) have reported that female Japanese medaka, Oryzias latipes, remain near a target male seen courting a receptive female in preference to a target male seen near a non-receptive female (e.g. a female that had just recently spawned with another male). When a receptive model female spawned, focal females preferred the spawning target male, when a receptive female failed to spawn focal females preferred the target male with a higher courtship rate. Howard et al. (1998), in a paper primarily concerned with other matters, examined effects on focal female medakas' affiliative preferences of seeing a previously non-preferred male mate with a recently mated model female. They failed to find evidence of mate-choice copying.

\subsection{Female Japanese quail}

Japanese quail (Coturnix japonica) like guppies, are useful animals for laboratory investigations of sexual behaviour. Much is known both of the hormonal basis of their sexual behaviour (AdkinsRegan, 1995) and stimulus control of their mate selection (Domjan and Hall, 1986). Like guppies, mature quail will court and mate in the laboratory essentially whenever given an opportunity to do so. Consequently, experiments are possible on social influences affecting mate choice using Japanese quail as subjects that would be impossible with most avian or mammalian species.

In our experiments, we used an enclosure (Fig. 2) similar to that which Dugatkin had used to examine mate choice in guppies (Fig. 1).

Each experiment consisted of three, $10 \mathrm{~min}$ phases: (1) a pre-test that we used to determine each focal animal's preference between two members of the opposite sex (target animals); (2) an observation period during which a focal animal was confined in the holding cage illustrated in Fig. 2 and given an opportunity to observe one of its two target animals remain alone and the other interact with a member of the same sex as the focal animal (a model animal); and (3) a post-test during which the focal animal chose for a second time between the same two target animals it had chosen between during the pre-test. 


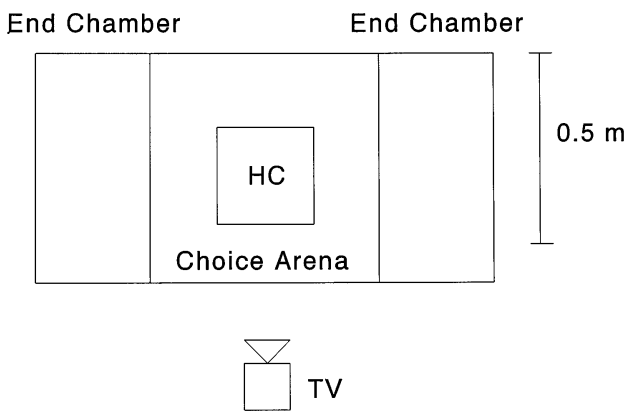

Fig. 2. Overhead schematic of apparatus used by White and Galef to study social influences on mate choice in Japanese quail.

In our first experiment (Galef and White, 1998), we determined whether a focal female quail would increase her preference for a target male that she had seen court and mate with a model female during the observation period. During the observation period, half of the focal females watched their respective non-preferred males (i.e. the male with whom they had spent less time during the pre-test) court and mate with a model female; the rest of the focal females we treated exactly as we had treated the first group except that, during the observation period, we did not place a model female with their non-preferred target males.

The results were exceptionally clear. Focal females that had seen their non-preferred target male court and mate with a model female during the observation period showed a highly significant increase between pre-test and post-test in the time that they spent with the target male they had seen court and mate. To the contrary, focal females whose non-preferred male did not court and mate during the observation period showed no change between pre-test and post-test in the time that they spent near him (Galef and White, 1998).

In subsequent experiments (Galef and White, 1998; White and Galef, 1999b), we found that focal females that could not see their non-preferred target male while he mated with a model female did not show an increase between pre-test and post-test in the time that they spent near him. We concluded that mating does not change the subsequent behaviour or appearance of males so as to make them more attractive to focal females.
We then changed the apparatus so that, during the observation period, the model female, like the focal female, was held in a transparent holding cage. This second holding cage, located in one end-chamber of the apparatus, had one opaque wall. When the cage containing the model female was positioned so that its opaque wall was located between focal and model females, the focal female saw a male courting, but no female; when the wall was located between the non-preferred male and the model female, the focal female saw a male and female together, but no courtship or mating; when the opaque wall faced the back of the cage, the focal female saw the male and female court, but not mate.

Results of such experiments were again quite clear (White and Galef, 1999b). If a focal female watched her non-preferred target male court, but could not see what he was courting, her preference for him was not affected. On the other hand, if a focal female saw either a non-preferred target male and model female simply standing near one another or a non-preferred target male court a female but not mount her, the focal female showed a significant increase in the time she spent with that target male during the post-test. We concluded that simply seeing a male and female in the same area is sufficient to cause a female to increase her preference for either that area or the male in it. Actual observation of copulation is not necessary for changes in females' mate choices to occur.

Further studies in which we reversed the locations of target males between the observation and post-test phases of the experiment revealed that focal females show an increase in preference for a particular male as a result of seeing him near a female, not just a preference for the place where the pair were seen (Galef and White, 1998; White and Galef, 1999b).

\subsection{Male Japanese quail}

Effects of observing mating proved to be sexspecific (White and Galef, 1999c). During the post-test, focal males that had seen a target female mate during the observation period were less, not more, attracted to her than they had been during the pre-test. 
We carried out the same sort of analysis with male quail that we had with female quail to discover what males had to see if they were to learn to avoid a previously preferred female. We found that necessary conditions for changing males' and females' mate choice are somewhat different. As in female quail, change in the response of male focal subjects resulted from seeing a target animal mate, not from changes in the target animal's appearance or behaviour as a result of mating (White and Galef, 1999c). However, a focal male quail had to see a target female courted by a male (not just standing near a male) to lose interest in her (White and Galef, 1999b,c).

It has become conventional in the literature on mate choice to equate a tendency on the part of two animals of opposite sex to affiliate with one another with their choosing one another as mates (Wagner, 1998). Obviously, that is not entirely satisfactory, and evidence is required of a correlation between measures of affiliation and choice of a copulatory partner before the proposition that studies that use affiliation as a dependent variable are relevant to questions of mate preference is accepted. We have provided such evidence in Japanese quail.

We first allowed females to chose between two males in a pre-test of affiliative preference. We then allowed the same females to choose between the same males as partners for copulation when they were tethered at opposite ends of an enclosure. We found that, regardless of the measure of female mate choice that we used (first male the female allowed to copulate with her, last male the female allowed to copulate with her, or male that a female copulated with most frequently), the male that a female spent longer near in the test of affiliation was the male with whom she preferred to copulate during the mate-choice test (White and Galef, 1999a). We found similarly that males free to copulate with both their preferred and non-preferred females, as determined by an affiliative-preference pre-test preferred to copulate with the female they remained closer to during a test of affiliative preference (White and Galef, 1999c).

In the studies described thus far, a focal animal saw a member of the opposite sex engage in some aspect of courtship and mating and changed its preference for the particular individual that it had seen mating. In an additional set of experiments (White and Galef, 2000), we asked whether a focal female that had observed a male mate with a model female changed her preference not just for the individual male she had seen mating, but for all males that were similar to him in appearance. Psychologists may consider such an experiment as a simple study of stimulus generalization. Behavioural ecologists will, we hope, see it as relevant to the question of whether social influence might play a role in the spread of mutant, sexually selected genes through a population.

We used a modified version of both the original apparatus (Fig. 3) and original procedure. The experiment was carried out in two rather than three stages. First, we confined a focal female in a holding cage that had two opaque walls oriented so that the focal female could see into the auxiliary cage (Fig. 3), but could not see into the two end compartments of the main enclosure that contained the target subjects. For $10 \mathrm{~min}$, the focal female observed either a male in the auxiliary enclosure mating with a model female, a male standing alone in the auxiliary enclosure, or an empty auxiliary enclosure. Then we lowered an opaque partition between the auxiliary enclosure and the central compartment of the main enclo-

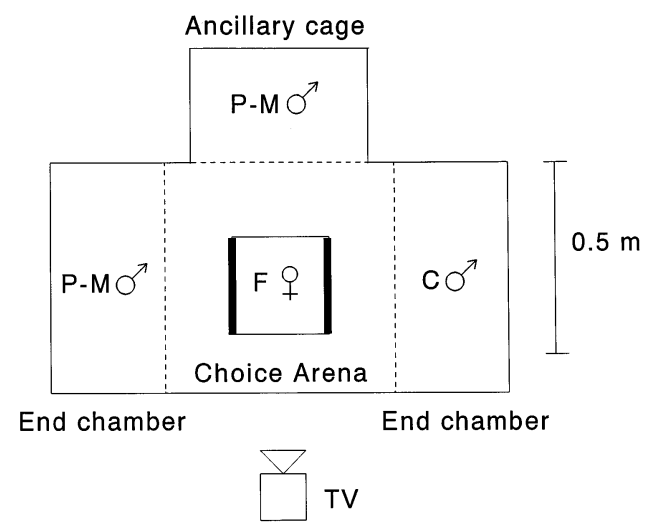

Fig. 3. Overhead schematic of apparatus used by White and Galef to study the generality of socially learned mate preferences in Japanese quail. 
sure, freed the focal female from the holding cage, and gave her a $10 \mathrm{~min}$ choice test between two target males, one in each end compartment.

Some of the hundreds of quail that we had brought into our laboratory to participate in experiments were feather-colour mutants; they had one or two unmelanated primaries on each wing, or a small unmelanated spot on the breast. It is an easy matter to create 'pseudo-mutant' quail by gluing some feathers taken from an albino quail onto a normal quail.

We allowed focal female quail to see a pseudomutant male in the auxiliary compartment either mating with a model female or standing alone. Then each focal female chose between two new quail, one a pseudo-mutant and the other a normal-looking male that had three normal feathers glued to it. We found that those focal females that had seen a pseudo-mutant male mate with a model female were more likely to affiliate with another pseudo-mutant male than were those focal females that had seen an empty auxiliary cage or a pseudo-mutant male standing alone in the auxiliary cage (White and Galef, 2000). Thus, we have provided evidence of a social or cultural process that could substantially accelerate the rate of spread of mutant genes through a population.

\section{Conclusion}

Empirical investigation of the role of social interactions in guiding mate selection is still in its infancy. A mere handful of laboratory model systems have been developed, and even these are in early stages of exploration. The greater challenge of determining how social interactions modify mate choices in free-living animals has only rarely been faced, and we have essentially no information on how public information impacts reproductive success in natural populations. Theoretical models of social influences on mate choice have outdistanced the empirical data base. There is much work to be done to begin to redress imbalances between theoretical and empirical, proximal and ultimate, and laboratory and field studies in the area.

\section{Acknowledgements}

Preparation of this manuscript was facilitated by a grant from the Natural Sciences and Engineering Research Council of Canada to B.G.G., Jr., and a McMaster University Richard Fuller Memorial Scholarship for Science to D.J.W.

\section{References}

Adkins-Regan, E., 1995. Predictors of fertilization in the Japanese quail (Coturnix japonica). Anim. Behav. 50, 1405-1415.

Boyd, R., Richerson, P.J., 1985. Culture and the Evolutionary Process. University of Chicago press, Chicago.

Bradbury, J.W., Gibson, R.M., 1983. Leks and mate choice. In: Bateson, P. (Ed.), Mate Choice. Cambridge, University Cambridge, pp. 109-140.

Brooks, R., 1996. Copying and repeatability of mate choice. Behav. Ecol. Sociobiol. 39, 323-329.

Brooks, R., 1998. The importance of mate copying and cultural inheritance of mating preferences. Trends Ecol. Evol. $13,45-46$.

Clutton-Brock, T.H., Hiraiwa-Hasegawa, M., Robertson, A., 1989. Mate choice on fallow deer leks. Nature 340, 463465.

Clutton-Brock, T., McComb, K., 1993. Experimental tests of copying and mate choice in fallow deer (Dama dama). Behav. Ecol. 4, 191-193.

DeMartini, E.E., 1987. Paternal defense, cannibalism and polygamy: factors influencing the reproductive success of painted greenling (Pisces, Hexagrammidae). Anim. Behav. 34, 1145-1158.

Domjan, M., Hall, S., 1986. Determinants of social proximity in Japanese quail (Coturnix coturnix japonica): Male behavior. J. Comp. Psych. 100, 59-67.

Dugatkin, L.A., 1992. Sexual selection and imitation: females copy the mate choice of others. Am. Nat. 139, 1384-1389.

Dugatkin, L.A., 1996a. Copying and mate choice. In: Heyes, C.M., Galef, B.G., Jr. (Eds.), Social Learning in Animals: the Roots of Culture. Academic Press, San Diego, pp. 85-106.

Dugatkin, L.A., 1996b. The interface between culturally-based preferences and genetic preferences: female mate choice in Poecilia reticulata. Proc. Natl. Acad. Sci.USA 93, 27702773.

Dugatkin, L.A., 1998. Genes, copying, and female mate choice: shifting thresholds. Behav. Ecol. 9, 323-327.

Dugatkin, L.A., Godin, J.-G.J., 1992. Reversal of female mate choice by copying in the guppy (Poecilia reticulata). Proc. R. Soc. Lond. B 249, 179-184.

Dugatkin, L.A., Godin, J.-G.J., 1993. Female mate copying in the guppy (Poecilia reticulata); age-dependent effects. Behav. Ecol. 4, 289-292. 
Dugatkin, L.A., Godin, J.-G.J., 1998. Effects of hunger on mate-choice copying in the guppy. Ethology 104, 194-202.

Fricke, H.W., 1980. Control of different mating systems in a coral reef fish by one environmental factor. Anim. Behav. 28, 561-569.

Galef, B.G., Jr., 1976. Social transmission of acquired behavior: a discussion of tradition and social learning in vertebrates. Adv. Stud. Behav. 6, 77-100.

Galef, B.G., Jr., 1984. Reciprocal heuristics: a discussion of the relationship of the study of learned behavior in laboratory and field. Learn. Motiv. 15, 479-493.

Galef, B.G., 1985. Direct and indirect behavioral processes for the social transmission of food avoidance. In: Bronstein, P., Braveman, N.S. (Eds.), Experimental Assessments and Clinical Applications of Conditioned Food Aversions. New York Academy of Sciences, New York, pp. 203-215.

Galef, B.G., Jr., White, D.J., 1998. Mate-choice copying in Japanese quail, Coturnix coturnix japonica. Anim. Behav. $55,545-552$.

Gibson, R.M., Bradbury, J.W., Vehrencamp, S.L., 1991. Mate choice in lekking sage grouse: the roles of vocal display, female site fidelity and copying. Behav. Ecol. 2, 165-180.

Gibson, R.M., Hoglund, J., 1992. Copying and sexual selection. Trends Ecol. Evol. 7, 229-231.

Goldschmidt, T., Bakker, C.M., Feuth-De Bruijn, E., 1993. Selective copying in mate choice of female sticklebacks. Anim. Behav. 45, 541-547.

Grant, J.W.A., Green, L.D., 1996. Mate copying versus preference for actively courting males by female Japanese medaka (Oryzias latipes). Behav. Ecol. 7, 165-167.

Hoglund, J., Alatalo, R.V., Gibson, R.M., Lunberg, A., 1995. Mate-choice copying in black grouse. Anim. Behav. 49, $1627-1633$.

Hoglund, J., Alatalo, R.V., Lundberg, R.M., 1990. Copying the mate choice of others? Observations on female black grouse. Behaviour 114, 221-2314.

Houde, A.E., 1997. Sex, color, and mate choice in guppies. Princeton University: Princeton.

Howard, R.D., Martens, S.A., Innes, S.A., Drnevich, J.M., Hale, J., 1998. Mate choice and mate competition influence male body size in Japanese medaka. Anim. Behav. 55, $1151-1163$.

Jamieson, I., 1995. Do female fish prefer to spawn in nests with eggs for reasons of mate choice copying or egg survival. Am. Nat. 145, 824-832.

Jamieson, I.G., Colgan, P.W., 1989. Eggs in the nests of males and their effect on mate choice in the three-spined stickleback. Anim. Behav. 38, 859-865.

Keister, R., 1979. Conspecifics as cues: A mechanism for habitat selection in the Panamanian grass anole (Anolis auratus). Behav. Ecol. Sociobiol. 5, 323-330.

Kirkpatrick, M., Dugatkin, L.A., 1994. Sexual selection and the evolutionary effects of copying mate choice. Behav. Ecol. Sociobiol. 34, 443-449.

Lafleur, D.L., Lozano, G.A., Sclafani, M., 1997. Female matechoice copying in guppies, Poecilia reticulata: A re-evaluation. Anim. Behav. 54, 579-586.
Laland, K., 1994a. Sexual selection with a culturally transmitted mating preference. Theor. Pop. Biol. 45, 1-15.

Laland, K.N., 1994b. On the evolutionary consequences of sexual imprinting. Evol. 48, 477-489.

Laland, K., Richerson, P.J., Boyd, R., 1993. Animal social learning: toward a new theoretical approach. Perspectives in Ethology 10, 249-277.

Laland, K., Richerson, P.J., Boyd, R., 1996. Developing a theory of animal social learning. In: Heyes, C.M., Galef, B.G., Jr. (Eds.), Social Learning in Animals: the Roots of Culture. Academic Press, San Diego, pp. 129-154.

Losey, G.S., Stanton, F.G., Telecky, T.M., Tyler III, W.A., and the Zoology 691 Graduate Seminar Class. 1986. Copying others, an evolutionarily stable strategy for mate choice: A model. Am. Nat., 128: 653-664

McComb, K., Clutton-Brock, T., 1994. Is mate-choice copying or aggregation responsible for skewed distributions of females on leks? Proc. R. Soc. Lond. B 255, 13-18.

Patriquin-Meldrum, K.J., Godin, J.-G.J., 1998. Do female three-spined sticklebacks copy the mate choices of others? Am. Nat. 151, 570-577.

Pruett-Jones, S., 1992. Independent versus non-independent mate choice: do females copy each other? Am. Nat. 140, $1000-1009$.

Ridley, M., Rechten, C., 1981. Female sticklebacks prefer to spawn with males whose nests contain eggs. Behaviour 76, $152-161$.

Schlupp, I., Marler, C., Ryan, M.J., 1994. Benefit to male sailfin mollies of mating with heterospecific females. Science 263, 373-374.

Sikkel, P.C., 1989. Egg presence and developmental stage influence spawning-site choice by female garibaldi. Anim. Behav. 38, 447-456.

Valone, T.J., 1989. Group foraging, public information, and patch estimation. Oikos 56, 357-363.

Wade, M.J., Pruett-Jones, S.G., 1990. Female copying increases the variance in male mating success. Proc. Natl. Acad. Sci. USA 87, 5749-5753.

Wagner, W.E., Jr., 1998. Measuring female mating preferences. Anim. Behav. 55, 1029-1042.

White, D.J. and Galef Jr., B.G., 1999a. Affiliative preferences are stable and predict mate choice in both sexes of Japanese quail, Coturnix japonica, Anim. Behav.

White, D.J., Galef, B.G., Jr., 1999b. Mate-choice copying and conspecific cueing in Japanese quail, Coturnix Coturnix japonica. Anim. Behav. 57, 465-473.

White, D.J., Galef, B.G., Jr., 1999c. Social effects on mate choices of male Japanese quail, Coturnix japonica. Anim. Behav. 57, 1005-1012.

White, D.J. and Galef, B.G., 2000. Culture in quail: Social influences on mate choice in female Coturnix japonica, Anim. Behav. 59, 975-979.

Wiley, R.H., 1991. Lekking in birds and mammals: behavioral and evolutionary issues. Adv. Stud. Behav. 20, 201-291.

Witte, K., Ryan, M.J., 1998. Male body length influences mate-choice copying in the sailfin molly Poecilia latipinna. Behav. Ecol. 9, 534-539. 